\title{
A multicenter intertrochanteric fracture study in the elderly: Hemiarthroplasty versus proximal femoral nailing
}

\author{
Yakup Ekinci, $\mathrm{MD}^{1,2,3,4}$, Kaan Gürbüz, $\mathrm{MD}^{1,2} \mathbb{D}$, Sabri Batın, $\mathrm{MD}^{1,2,5}$, Murat Kahraman, $\mathrm{MD}^{2,6} \mathbb{D}^{\mathbb{D}}$, \\ Fatih Doğar, $\mathrm{MD}^{1,6,7}$ (D), Zeliha Kaya Erten, $\mathrm{PhD}^{8}$ (D) \\ ${ }^{1}$ Department of Orthopedics and Traumatology, Kayseri Training and Research Hospital, Kayseri, Turkey \\ ${ }^{2}$ Department of Orthopedics and Traumatology, Kayseri City Training and Research Hospital, Kayseri, Turkey \\ ${ }^{3}$ Department of Orthopedics and Traumatology, Başkale Public Hospital, Van, Turkey \\ ${ }^{4}$ Department of Orthopedics and Traumatology, Develi State Hospital, Kayseri, Turkey \\ ${ }^{5}$ Department of Orthopedics and Traumatology, Batman State Hospital, Turkey \\ ${ }^{6}$ Department of Orthopedics and Traumatology, Necip Fazıl State Hospital, Kahramanmaraş, Turkey \\ ${ }^{7}$ Department of Orthopedics and Traumatology, Sütçü İmam University Hospital, Kahramanmaraş, Turkey \\ ${ }^{8}$ Department of Nursing, Health Sciences Faculty, Nuh Naci Yazgan University, Kayseri, Turkey
}

With the aging population, the incidence rate of osteoporosis has been rapidly increasing. ${ }^{[1]}$ These fractures are predicted to reach 2.6 million in 2025 and 4.5 million in 2050 worldwide. ${ }^{[2]}$ The incidence of these fractures, which frequently occur due to falls, is two-three times higher in females than in males. ${ }^{[3]}$ Intertrochanteric fractures, which are usually unstable, can only be treated surgically. ${ }^{[4]}$

The key point of the surgical treatment is stable fixation and early mobilization with full-weight bearing. However, this is not always as easy as it seems. Most of the patients are elderly, osteoporotic, with additional morbidity and limited mobilization, and prone to complications. ${ }^{[5,6]}$ Therefore, there is no consensus regarding the treatment of

Received: November 19, 2019

Accepted: February 05, 2020

Published online: June 18, 2020

Correspondence: Yakup Ekinci, MD. Kayseri Şehir Eğitim ve Araştırma Hastanesi Ortopedi ve Travmatoloji Kliniği, 38080 Kocasinan, Kayseri, Türkiye.

E-mail: belduya@gmail.com

Doi: 10.5606/ehc.2020.72421

Citation: Ekinci Y, Gürbüz K, Batın S, Kahraman M, Doğar F, Kaya Erten Z. A multicenter intertrochanteric fracture study in the elderly: Hemiarthroplasty versus proximal femoral nailing. Jt Dis Relat Surg 2020;31(2):209-217.

This study was orally presented at the $29^{\text {th }}$ Turkish National Congress of Orthopaedics and Traumatology in Antalya on 22-27 October 2019, Antalya, Turkey.

\section{ABSTRACT}

Objectives: This study aims to compare the clinical and functional results of intertrochanteric femoral fractures treated with bipolar hemiarthroplasty (BHA) or proximal femoral nailing (PFN) in elderly patients.

Patients and methods: This multicenter, prospectively followed-up, retrospectively compared cohort-type study included 308 patients (81 males, 227 females; mean age $78.4 \pm 7.2$ years; range, 65 to 95 years) who were treated with BHA or PFN for intertrochanteric fractures by five orthopedic surgeons in four provinces and seven clinics between January 2014 and May 2018. Clinical follow-up was performed at third week, third and sixth months, and at the end of the first and second years. The American Society of Anesthesiologists for preoperative status, Singh index for bone quality, and Harris Hip Score (HHS) for functional outcomes were evaluated.

Results: While 156 patients (38 males, 118 females; mean age $77.7 \pm 5.9$ ) were treated with BHA, 152 patients ( 43 males, 109 females; mean age $79 \pm 6.1$ ) were treated with PFN. While there was no significant difference between the two groups in terms of total HHS, a significant difference was found in the sub-parameters $(\mathrm{p}<0.001)$. Good and excellent results were found in $78.2 \%$ of BHA and $86.2 \%$ of PFN patients. Mortality rates were similar at the end of two years (14\% and $13.6 \%$, respectively).

Conclusion: In general, clinical and functional outcomes of BHA and PFN are similar. The rates of pulmonary embolism and deep vein thrombosis are significantly higher in BHA. However, BHA is advantageous in terms of operation time and early weight bearing compared to PFN.

Keywords: Harris Hip Score, hemiarthroplasty, intertrochanteric fracture, proximal femur nail.

intertrochanteric fractures and the most appropriate treatment according to the patient's age and fracture type is still not clear. To date, treatment methods such as dynamic hip screw (DHS), proximal femoral 
nail (PFN) antirotation, unipolar and bipolar hemiarthroplasty (BHA), total arthroplasty, and external fixation have been used. . $2,4,6-8]^{-}$

Although the research of biomechanical properties has shown that intramedullary nails are more stable due to the shorter lever arm, it is known that failure to achieve early weight bearing is an important problem particularly in this type of fracture in which elderly and osteoporotic patients are affected. ${ }^{[9,10]}$ Hemiarthroplasty, which has been used frequently in the treatment of intertrochanteric fractures since the 1970s, cannot be considered an ideal treatment. ${ }^{[10]}$ Despite the many studies on this subject, large case series comparing PFN versus BHA are rarely seen in the literature. Therefore, in this study, we aimed to compare the clinical and functional results of intertrochanteric femoral fractures treated with BHA or PFN in elderly patients.

\section{PATIENTS AND METHODS}

This multi-center, prospectively followed up, retrospectively compared cohort-type study was conducted by five orthopedic surgeons in four provinces and seven hospitals. Between January 2014 and May 2018, 2,221 patients underwent hemiarthroplasty and 1,659 patients underwent PFN for intertrochanteric femoral fractures. The study protocol was approved by the Erciyes University Ethics Committee (numbered 2018/545). A written informed consent was obtained from each patient. The study was conducted in accordance with the principles of the Declaration of Helsinki.

Patients over 65 years of age and treated with $\mathrm{BHA}$ and PFN for intertrochanteric fractures were included in the study. Patients under 65 years of age; with pathological fractures, poly trauma-related fractures, or walking difficulties before immobility or fracture; or that had not been followed-up for two years postoperatively were excluded. As a result of the power analysis, the sample size was found to be 92 for each group. Thus a total of 308 patients (81 males, 227 females; mean age $78.4 \pm 7.2$ years; range, 65 to 95 years) were included, 156 patients ( 38 males, 118 females; mean age $77.7 \pm 5.9)$ constituting the BHA group and 152 patients (43 males, 109 females; mean age 79 \pm 6.1 ) constituting the PFN group (Figure 1).

The medical records of the patients included in the study were collected from patient files and the Hospital Information Management System. The questionnaires were administered during the patients' check-ups in the outpatient polyclinic. The American Society of Anesthesiologists (ASA) classification was used to evaluate the preoperative health status of the

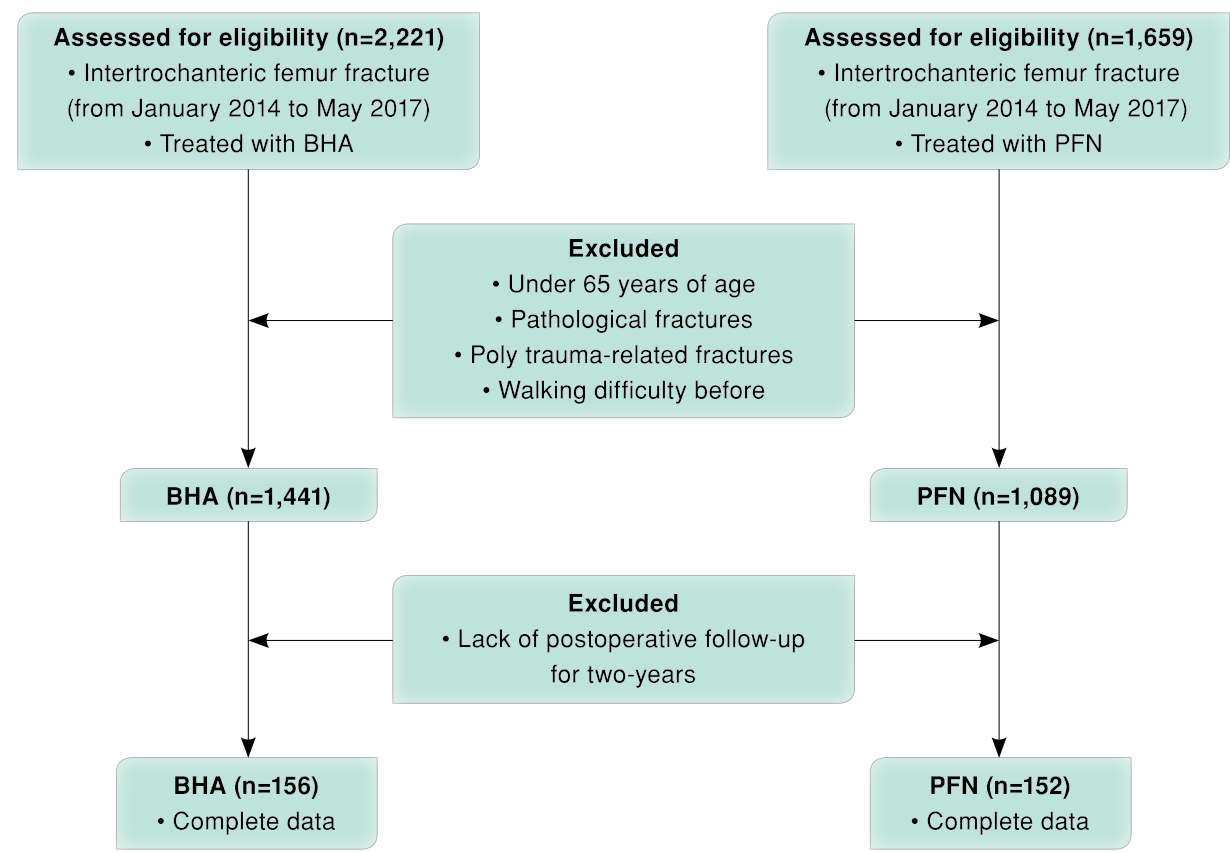

FIGURE 1. Flow diagram of study inclusion and exclusion criteria.

BHA: Bipolar hemiarthroplasty; PFN: Proximal femoral nailing. 
patients and bone quality was evaluated using the Singh index. Fracture classification was performed by two orthopedic surgeons on an intraobserver basis and one radiologist on an interobserver basis using the Arbeitsgemeinschaft für Osteosynthesefragen/ Orthopaedic Trauma Association (AO/OTA) classification (Table I). Clinical follow-up was performed at the third week, third and sixth months, and at the end of the first and second years. ASA score for preoperative status, Singh index for bone quality, and Harris Hip Score (HHS) for functional outcomes were evaluated. The final postoperative follow-up of the patients was performed using anteroposterior and lateral X-rays, while the functional evaluation was performed by the HHS questionnaire.

Bipolar hemiarthroplasty was performed under general or spinal anesthesia or sacral plexus block according to the decision of the anesthesiologist, with the fracture side up in the lateral decubitus position by a posterolateral approach. In patients with intertrochanteric fracture after insertion of a

\section{TABLE I}

Comparison of baseline characteristics between bipolar hemiarthroplasty and proximal femoral nailing

\begin{tabular}{|c|c|c|c|c|c|c|c|c|c|c|}
\hline \multirow[b]{2}{*}{ Characteristics } & \multicolumn{4}{|c|}{ BHA group $(n=156)$} & \multicolumn{4}{|c|}{ PFN group $(n=152)$} & \multirow[b]{2}{*}{ Statistics } & \multirow[b]{2}{*}{$p$} \\
\hline & $\mathrm{n}$ & $\%$ & Mean \pm SD & Median & $\mathrm{n}$ & $\%$ & Mean $\pm S D$ & Median & & \\
\hline Age (year) & & & $77.7 \pm 5.9$ & & & & $79 \pm 6.1$ & & $-0.411^{*}$ & 0.510 \\
\hline Gender & & & & & & & & & $1.799^{* *}$ & 0.431 \\
\hline Female & 118 & 75.6 & & & 109 & 71.7 & & & & \\
\hline Male & 38 & 24.4 & & & 43 & 28.3 & & & & \\
\hline Side & & & & & & & & & $0.006^{\star *}$ & 0.955 \\
\hline Left & 94 & 60.3 & & & 87 & 57.2 & & & & \\
\hline Right & 62 & 39.7 & & & 65 & 42.8 & & & & \\
\hline \multicolumn{11}{|l|}{ Etiology } \\
\hline Fallen from the standing height & 17 & 10.9 & & & 13 & 8.5 & & & $1.202^{* *}$ & 0.039 \\
\hline Fallen from high height & 30 & 19.2 & & & 65 & 42.8 & & & $33.7^{* *}$ & $<0.001$ \\
\hline Road accident & 38 & 24.4 & & & 42 & 27.6 & & & $4.531^{\star *}$ & 0.745 \\
\hline Assault & 27 & 17.3 & & & 11 & 7.2 & & & $6.003^{\star *}$ & 0.143 \\
\hline Others & 44 & 28.2 & & & 21 & 13.8 & & & $22.6^{\star *}$ & $<0.001$ \\
\hline ASA score & & & & & & & & & $5.346^{\star \star}$ & 0.342 \\
\hline 1 & 3 & 1.9 & & & 7 & 4.6 & & & & \\
\hline 2 & 87 & 55.8 & & & 75 & 49.3 & & & & \\
\hline 3 & 59 & 37.8 & & & 64 & 42.1 & & & & \\
\hline 4 & 7 & 4.5 & & & 6 & 3.9 & & & & \\
\hline AO/OTA classification & & & & & & & & & $2.314^{\star *}$ & 0.068 \\
\hline $31 \mathrm{~A} 1.2$ & 5 & 3.2 & & & 3 & 2 & & & & \\
\hline $31 \mathrm{~A} 1.3$ & 26 & 16.7 & & & 36 & 23.7 & & & & \\
\hline $31 \mathrm{~A} 2.2$ & 38 & 24.4 & & & 42 & 27.6 & & & & \\
\hline $31 \mathrm{~A} 2.3$ & 84 & 53.8 & & & 62 & 40.8 & & & & \\
\hline 31А3.1 & 1 & 0.6 & & & 2 & 1.3 & & & & \\
\hline $31 \mathrm{~A} 3.2$ & - & - & & & 5 & 3.3 & & & & \\
\hline 31 АЗ.3 & 2 & 1.3 & & & 2 & 1.3 & & & & \\
\hline Singh index & & & & 3.0 & & & & 3.0 & & \\
\hline \multicolumn{11}{|l|}{ Comorbidities } \\
\hline Hypertension & 89 & 57 & & & 69 & 45.4 & & & $6.879^{* *}$ & 0.005 \\
\hline Cardiovascular disease & 48 & 30.8 & & & 63 & 41.4 & & & $0.803^{* *}$ & 0.346 \\
\hline Diabetes mellitus & 97 & 62.2 & & & 102 & 67.1 & & & $7.456^{\star *}$ & 0.005 \\
\hline Pulmonary disease & 34 & 21.8 & & & 29 & 19.1 & & & $1.211^{* *}$ & 0.563 \\
\hline Cerebrovascular disease & 18 & 11.5 & & & 23 & 15.1 & & & $2.832^{* *}$ & 0.27 \\
\hline Others & 49 & 31.4 & & & 19 & 12.5 & & & $0.398^{* *}$ & 0.732 \\
\hline
\end{tabular}

BHA: Bipolar hemiarthroplasty; PFN: Proximal femoral nailing; SD: Standard deviation; ASA: American Society of Anesthesiologists; AO/OTA: Arbeitsgemeinschaft für Osteosynthesefragen/Orthopaedic Trauma Association; ${ }^{*} \mathrm{~T}$ test. ${ }^{\star \star}$ Chi-Square test. 

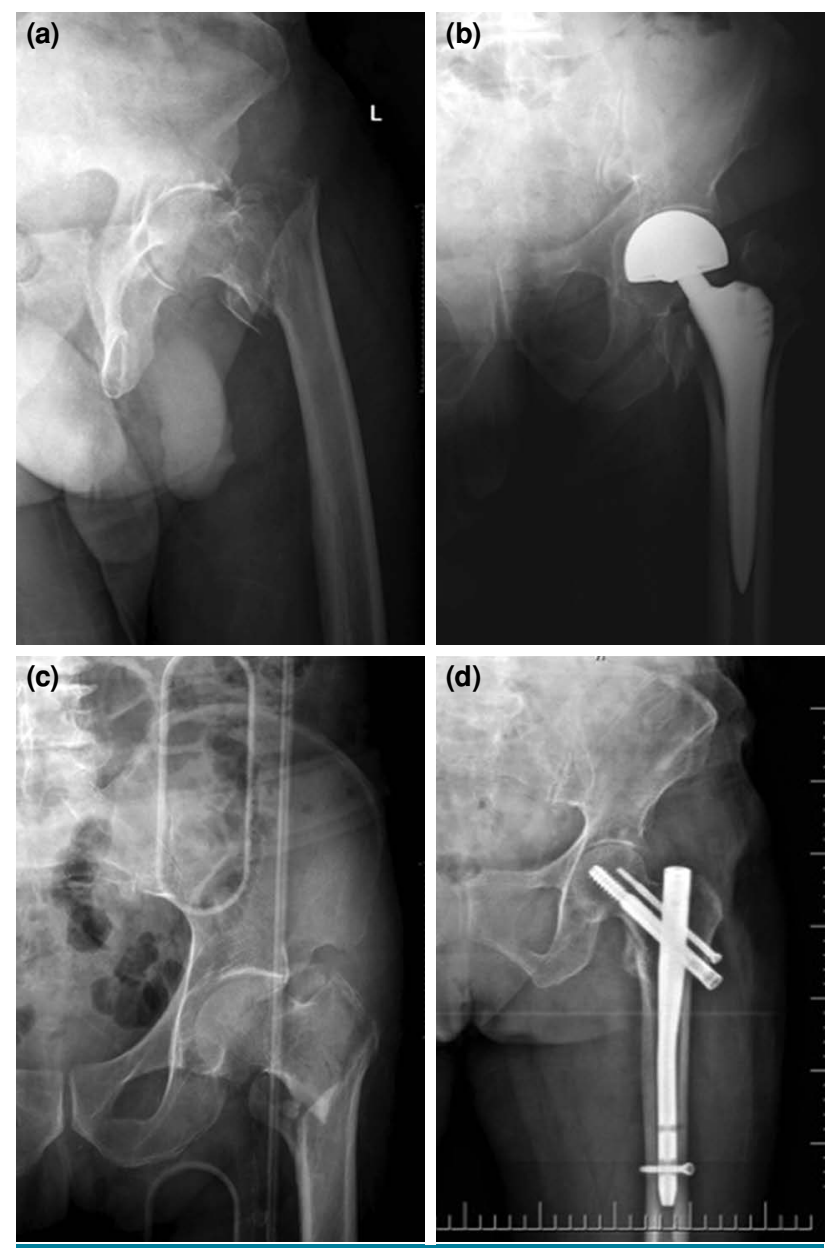

FIGURE 2. (a) Anteroposterior radiograph showing an unstable intertrochanteric fracture of left hip in a 76-year-old male patient who fell at home. (b) Radiograph two years after hemiarthroplasty. (c) Anteroposterior radiograph showing an unstable intertrochanteric fracture of left hip in a 77-year-old female patient who fell at home. (d) Radiograph 15 months after fixation with a proximal femoral nail.

prosthesis, fixation was achieved by reduction with cable and/or cable plate (Figure 2).

Proximal femoral nail was performed under general or spinal anesthesia or sacral plexus block on a traction table with G-arm fluoroscopy by the standard surgical method (Figure 2).

In all patients, $1 \mathrm{~g}$ of intramuscular cefazolin sodium (Sefazol ${ }^{\oplus}$; M. Nevzat İlaç Sanayi, Istanbul, Turkey) was administered as antibiotic prophylaxis two hours before surgery. The patients were mobilized on postoperative day one or two under the guidance of an orthopedic surgeon. Bipolar hemiarthroplasty patients were mobilized with full weight bearing on the first day. The use of a walker was terminated at four weeks. In PFN patients, partial weight bearing was started after one month. At six weeks postoperatively, full load was allowed. The use of crutches was terminated at 10 weeks. After discharge, the patient was followed-up at the outpatient clinic after three weeks, three months, six months, one year, and two years.

\section{Statistical analysis}

The statistics were analyzed using the PASW version 17.0 software (SPSS Inc., Chicago, IL, USA). Kolmogorov-Smirnov tests were used to check the continuous variables for Gaussian distribution. T-tests were used for all the continuous variables with a Gaussian distribution. For the continuous variables without a Gaussian distribution, Wilcoxon statistics (Mann-Whitney $U$ test) were used. For the ranking variables, Pearson chi-square tests were used to evaluate significance. The level of statistical significance was set at a two-sided $p$ value of 0.05 .

\section{RESULTS}

The age distributions of the BHA and PFN groups were similar $(\mathrm{p}>0.05)$ (Table I). The mean follow-up period was $27.6 \pm 7.3$ months (range, 24.1 to 39.5 months). Follow-up time was $24.2 \pm 6.3$ months (range, 24.1 to 39.4 months) in the BHA group and $31.6 \pm 11.2$ months (range, 24.5 to 39.5 months) in the PFN group. The difference between the two groups was statistically significant ( $\mathrm{p}=0.034$, $\mathrm{t}$-test).

The main characteristics of the patients in the groups are shown in Table I. Accordingly, gender, age at the time of fracture, age at the last follow-up, fracture side, fracture etiology, previous fracture prior to hip fracture, ASA score, AO/OTA fracture classification, Singh index, and comorbidity parameters of the patients did not differ significantly between the groups (Table I and II).

Although the PFN group had higher HHSs, no significant difference was found between the two groups (Figures 3 and 4). However, when the sub-headings of the scoring system were evaluated separately, arthroplasty was significantly superior in terms of the pain, walking distance, and stairs parameters $(\mathrm{p}<0.001)$.

As shown in Figures 3, HHS decreased with age. This is due to the negative effect of aging on physical activity. While the mean score of patients under 70 years of age was 84.7 , it decreased to 78.5 in the 85-89 age range and to 61.9 in patients older than 90 years.

Complications were seen in a total of 79 patients (Table III). Complications of the patients that died 


\begin{tabular}{|c|c|c|c|c|c|c|c|c|c|c|}
\hline \multirow[b]{3}{*}{ Characteristics } & \multirow{2}{*}{\multicolumn{4}{|c|}{$\begin{array}{l}\text { TABLE II } \\
\text { variables between bipolar } h \\
\text { BHA group }(n=156)\end{array}$}} & \multirow{2}{*}{\multicolumn{4}{|c|}{ PFN group $(n=152)$}} & \multirow[b]{3}{*}{ Statistics } & \multirow[b]{3}{*}{$p$} \\
\hline & & & & & & & & & & \\
\hline & $\mathrm{n}$ & $\%$ & Mean \pm SD & Median & $\mathrm{n}$ & $\%$ & Mean \pm SD & Median & & \\
\hline Anesthesia & & & & & & & & & $50.7^{*}$ & $<0.001$ \\
\hline General & 72 & 46.2 & & & 14 & 9.2 & & & & \\
\hline Spinal & 69 & 44.2 & & & 94 & 61.8 & & & & \\
\hline Sacral plexus block & 15 & 9.6 & & & 44 & 28.9 & & & & \\
\hline Time from injury to admission (hour) & & & & 17.2 & & & & 20.3 & $1,657.7 \dagger$ & 0.537 \\
\hline Time from injury to operation (hour) & & & & 10.3 & & & & 11.7 & $2,089.3 \dagger$ & 0.453 \\
\hline Operation time (hour) & & & & 0,63 & & & & 0,88 & $6,678.9 \dagger$ & $<0.001$ \\
\hline Blood loss during operation $(\mathrm{mL})$ & & & & 321.4 & & & & 78.9 & $6,487.5 \dagger$ & $<0.001$ \\
\hline Drainage volume from hemovac $(\mathrm{mL})$ & & & & 248.8 & & & & 102.7 & $5,345.2 \dagger$ & $<0.001$ \\
\hline $\begin{array}{l}\text { Blood transfusion during hospital } \\
\text { stay }(\mathrm{mL})\end{array}$ & & & & 614.4 & & & & 326.8 & $4,567.9 \dagger$ & $<0.001$ \\
\hline $\begin{array}{l}\text { Partial weight bearing and/or } \\
\text { walking (day) }\end{array}$ & & & & 1.8 & & & & 3.4 & $4,785.3+$ & $<0.001$ \\
\hline Hospital stay (day) & & & & 6.6 & & & & 5.9 & $8,567.6 \dagger$ & 0.703 \\
\hline Hemoglobin descending $(\mathrm{g} / \mathrm{dL})$ & & & $8.3 \pm 2.7$ & & & & $3.5 \pm 1.1$ & & $3.7 \ddagger$ & $<0.001$ \\
\hline Albumin descending (g) & & & $5.92 \pm 4.3$ & & & & $3.7 \pm 2.94$ & & $-1.453 \ddagger$ & 0.002 \\
\hline
\end{tabular}

were not evaluated. Complication rates were higher in the BHA group, but the difference was not significant compared with the PFN group $\left(\mathrm{p}=0.203, \chi^{2}=1.645\right)$.

The types of complications varied between the groups. For the PFN group, cut-out/migration was seen in five patients, malrotation in seven patients, and inadequate fixation requiring revision surgery in four patients. Nonunion or delayed union was not found radiologically. In the BHA group, malrotation was detected in two patients and the lower extremity length difference was more than $3 \mathrm{~cm}$ in four patients. In addition, symptomatic deep vein thrombosis (DVT) including pulmonary embolism was detected clinically and radiologically in 17 patients. However, this was seen only in three patients in the PFN group and was significantly higher when compared with the BHA

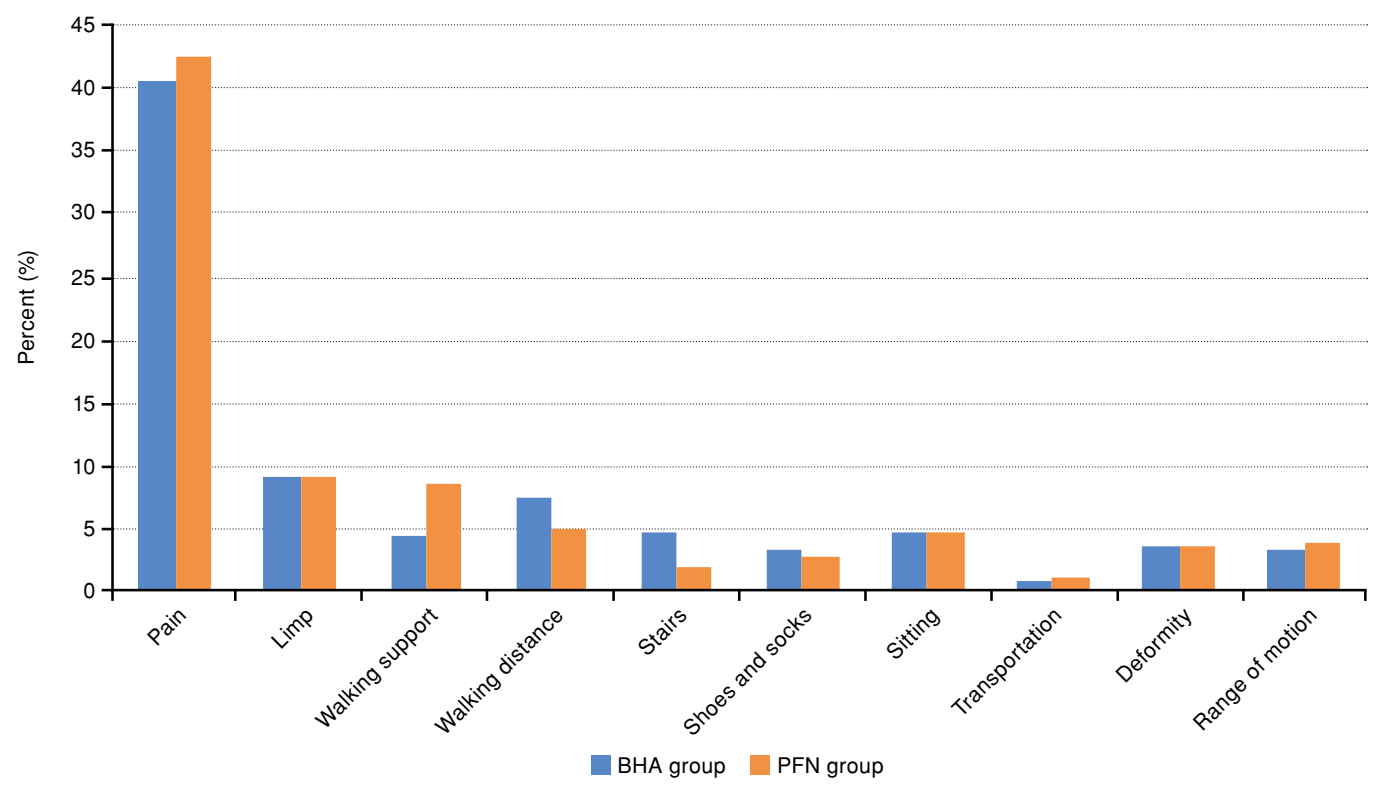

FIGURE 3. Distribution of Harris Hip Score in study groups.

BHA: Bipolar hemiarthroplasty; PFN: Proximal femoral nailing. 


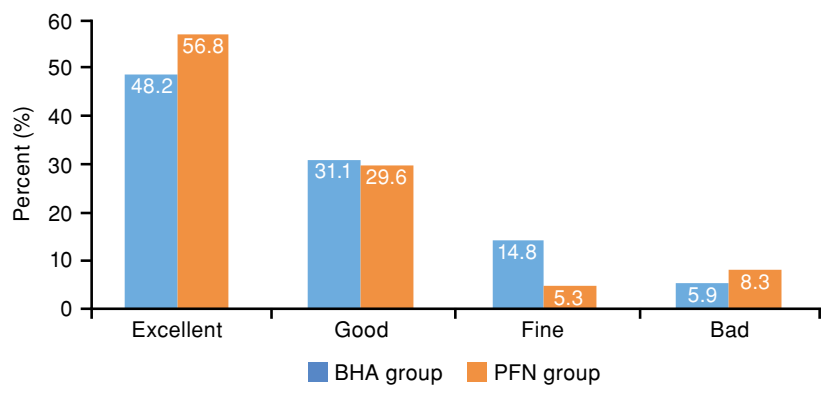

FIGURE 4. Ratio of Harris grade distribution in both groups. BHA: Bipolar hemiarthroplasty; PFN: Proximal femoral nailing.

group $\left(\mathrm{p}<0.001, \chi^{2}=23.6\right)$. Secondary revision surgery was performed in 15 patients for two dislocations, six deep infections, and seven periprosthetic fractures in the BHA group. Secondary revision surgery was performed in 22 patients including five with cut-out/migration, two with deep infections, 11 with periprosthetic fractures, and four with insufficient primary osteosynthesis in the PFN group. When the two groups were compared in terms of complications requiring revision surgery, no statistically significant difference was found $\left(\mathrm{p}=0.554, \chi^{2}=4.505\right)$.

The comparison of fracture types according to AO/OTA classification and Singh index grades between the $\mathrm{BHA}$ and PFN groups with complications is shown in (Figure 4).
According to the fracture types, the number of complications and Singh index values were not significantly different between the groups ( $p>0.05)$. A total of 41 patients (21 in the BHA group and 20 in the PFN group) died during the entire follow-up period. There was no statistically significant difference in the mortality rate between the two groups $(p=0.039$, $\chi^{2}$-test). The mortality rates were also not significantly different between the groups at first week, first month, third month, first year, or the last follow-up. However, although there was no significant difference at the end of the first year, the mortality rate in the PFN group was lower than that in the BHA group (Figure 5).

\section{DISCUSSION}

As with all fractures in elderly patients, it is difficult to obtain ideal treatment results because of low bone quality, additional morbidities, and mobilization problems in intertrochanteric femoral fractures. Although there are some differences in complications and mortality rates, there is no significant difference between BHA and PFN in elderly patients with intertrochanteric fractures in a great number of parameters during treatment.

There are many methods that can be used for intertrochanteric fractures and there are many reports comparing them in the literature. The use of

\begin{tabular}{|c|c|c|c|c|}
\hline \multicolumn{5}{|c|}{$\begin{array}{l}\text { TABLE III } \\
\text { plasty and p }\end{array}$} \\
\hline Characteristics & $\mathrm{BHA}(n=135)$ & PFN (n=132) & Statistics* & $p$ \\
\hline \multicolumn{5}{|c|}{ AO/OTA fracture classification } \\
\hline $31 \mathrm{~A} 1.2$ & $2 / 5$ & $-/ 3$ & 0.789 & 0.456 \\
\hline $31 \mathrm{~A} 1.3$ & $1 / 26$ & $5 / 36$ & 1.724 & 0.061 \\
\hline $31 \mathrm{~A} 2.2$ & $3 / 38$ & $9 / 42$ & 0.0645 & 0.076 \\
\hline $31 \mathrm{~A} 2.3$ & $35 / 84$ & $15 / 62$ & 0.3389 & 0.686 \\
\hline $31 \mathrm{~A} 3.1$ & $1 / 1$ & $1 / 2$ & 1.512 & 0.093 \\
\hline $31 \mathrm{~A} 3.2$ & $-/-$ & $4 / 5$ & 0.409 & 0.198 \\
\hline $31 \mathrm{A3.3}$ & $1 / 2$ & $2 / 2$ & 1.086 & 0.251 \\
\hline \multicolumn{5}{|l|}{ Singh index (n) } \\
\hline Grade I & $2 / 7$ & $1 / 11$ & 0.5784 & 0.234 \\
\hline Grade II & $5 / 13$ & $5 / 27$ & 0.0987 & 0.768 \\
\hline Grade III & $23 / 79$ & $19 / 65$ & 2.8976 & 0.078 \\
\hline Grade IV & $11 / 34$ & $8 / 23$ & 3.0098 & 0.045 \\
\hline Grade V & $2 / 2$ & $4 / 6$ & 0.6754 & 0.384 \\
\hline
\end{tabular}




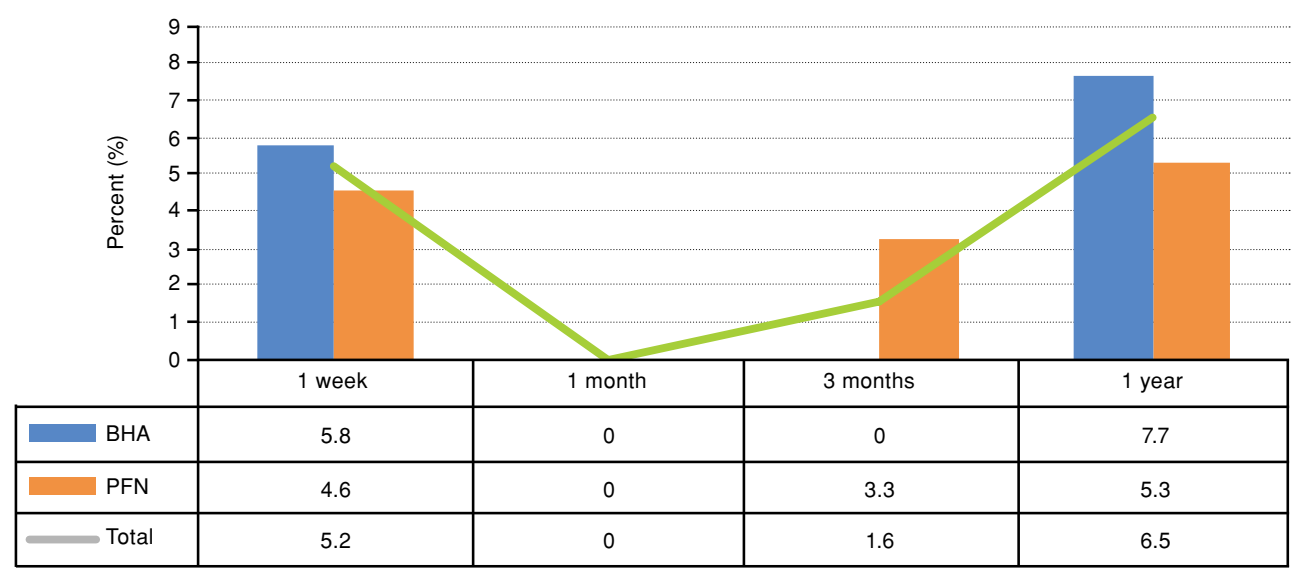

FIGURE 5. Distribution of mortality in study groups.

BHA: Bipolar hemiarthroplasty; PFN: Proximal femoral nailing.

DHS, which is one of these methods, has decreased considerably in elderly patients due to insufficient functional results, external rotation deformity, and high amount of shortness. ${ }^{[3,11-13]}$ Broos et al. ${ }^{[14]}$ reported that hemiarthroplasty patients had less mortality, shorter operative time, and better functional results than DHS and angled plate patients.

The hemiarthroplasty method, which has been popular for almost 50 years and the design of which has developed over time, is still used as the first choice by many orthopedic surgeons. On the other hand, osteosynthesis with proximal hip nailing is more effective in biomechanical studies due to its lower deformity rate in elderly patients. The number of surgeons advocating that it should be considered primarily increases with each passing day. ${ }^{[15,16]}$

Özkayın et al. ${ }^{[3]}$ reported higher HHSs in their hemiarthroplasty group for up to six months and higher values in their PFN group at 12 months. While these values increased in both groups at 18 months, the increase was greater in the PFN group. In addition, in contrast to our study, they reported that the operation time was shorter in PFN patients. ${ }^{[3]}$ In the literature, different results have been reported in terms of operation time, which we think is due to the inability to standardize the surgical time due to the uncertainty in the reduction of unstable fractures.

In their study involving 50 patients, Hari Prasad et al. ${ }^{[6]}$ reported that the amount of bleeding and the surgical time were lower in favor of PFN. Also, HHS was higher after hemiarthroplasty until the end of 12 months. However, we conclude that the low mean age of the patients is the most important factor affecting these results.
In their study including 86 patients, Desteli et al. ${ }^{[17]}$ stated that there was no significant difference between the two groups in their two-year follow-up. Similarly, the length of hospital stay was correlative to that in our study; they reported that the operation time was longer in the PFN group. In addition, according to social functioning measurements, the hemiarthroplasty group had more social functionality at three months, while the values of the groups were equal at 12 months. The PFN group had slightly higher social functioning despite the increase in both groups at 24 months. In their evaluation of the quality of life, they reported no significant difference, while scores never returned to preoperative levels after either surgical technique. ${ }^{[17]}$

Luo et al. ${ }^{[18]}$ reported that the mortality rate was $21.2 \%$ in the BHA group and $11.3 \%$ in the PFN group at one year. However, they also emphasized that PFN should not be abandoned due to minimal fixation failures.

Internal fixation causes further problems like cutout and collapse in elderly patients. The extent of this problem is so great that some surgeons prefer to use hemiarthroplasty. ${ }^{[3,19]} \mathrm{Kim}$ et al. ${ }^{[7]}$ reported that the mortality rates of their hemiarthroplasty and PFN groups were $20.6 \%$ and $13.8 \%$ at one year and $55 \%$ and $17 \%$ at three years, respectively, in their study of 58 patients.

In our study, the complication rate was slightly higher in the hemiarthroplasty group. However, the rate of symptomatic DVT, including pulmonary embolism, was significantly higher in the hemiarthroplasty group. We can say that the most important disadvantage of hemiarthroplasty 
compared to PFN is the development of DVT despite pharmacological and mechanical measures. Our mortality rate was $5.33 \%$ in the first week and it increased to $13.66 \%$ after two years.

The amount of intra- and postoperative early bleeding was significantly higher in patients undergoing hemiarthroplasty despite the shorter operative time. It may be difficult to regulate hemodynamics in patients with a high ASA score and in need of postoperative intensive care. Therefore, it would be more appropriate to use PFN with a much lower rate of both intra- and postoperative bleeding by evaluating such patients carefully. However, the mean operation time is longer in PFN applications and problems such as postoperative early weightbearing loss are encountered. In the elderly patient group, the short duration of surgery and intensive care unit stay, and early weight bearing are important in preventing mortality and morbidity.

Although the methods are similar in elderly patients in many respects in the long-term, early mobilization of the patient in the short-term will contribute to the patient's self-care, which will provide significant convenience particularly for the family. In addition, the necessity of using fluoroscopy in surgery seems to be a disadvantage for orthopedists, who are frequently exposed to radiation. Therefore, planning new studies including families and surgeons will contribute to clarifying this controversial issue.

There were some limitations of our study. First, multicenter patients were not able to receive postoperative standardized physical therapy and rehabilitation or complication management. Secondly, some patients were excluded due to a lack of a oneyear follow-up. This exclusion also procures the mortality and morbidity rates of the study decreased. Lastly, study groups could not be selected according to each fracture type in the AO/OTA classification.

In conclusion, the method allowing shorter duration of surgery, early weight bearing, and low bleeding, complication, and mortality rates is the most ideal method in elderly patients with intertrochanteric fractures. The rates of pulmonary embolism and DVT are significantly higher in BHA. However, BHA is advantageous in terms of operation time and allowing early weight bearing compared to PFN. Clinical and functional outcomes of BHA and PFN are similar. Therefore, the evaluation of each case and choice of the appropriate treatment method should be left to the surgeon's preference and experience.

\section{Declaration of conflicting interests}

The authors declared no conflicts of interest with respect to the authorship and/or publication of this article.

\section{Funding}

The authors received no financial support for the research and/or authorship of this article.

\section{REFERENCES}

1. Tokgöz MA, Atik OŞ, Esendağlı G, Öğüt B, Bozkurt HH. Is it possible that the pathogenesis of osteoarthritis could start with subchondral trabecular bone loss like osteoporosis? Eklem Hastalik Cerrahisi 2018;29:152-8.

2. Emami M, Manafi A, Hashemi B, Nemati A, Safari S. Comparison of intertrochanteric fracture fixation with dynamic hip screw and bipolar hemiarthroplasty techniques. Arch Bone Jt Surg 2013;1:14-7.

3. Özkayın N, Okçu G, Aktuğlu K. Intertrochanteric femur fractures in the elderly treated with either proximal femur nailing or hemiarthroplasty: A prospective randomised clinical study. Injury 2015;46:S3-8.

4. Paul O, Barker JU, Lane JM, Helfet DL, Lorich DG. Functional and radiographic outcomes of intertrochanteric hip fractures treated with calcar reduction, compression, and trochanteric entry nailing. J Orthop Trauma 2012;26:148-54.

5. Görmeli G, Korkmaz MF, Görmeli CA, Adanaş C, Karataş T, Şimşek SA. Comparison of femur intertrochanteric fracture fixation with hemiarthroplasty and proximal femoral nail systems. Ulus Travma Acil Cerrahi Derg 2015;21:503-8.

6. Hari Prasad S, Siddaram N Patil, Sarath Chandra P, Cecil Fernando A. Functional outcome of unstable intertrochanteric femur fracture in elderly osteoporotic patients treated by primary cemented bipolar hemiarthroplasty versus internal fixation with proximal femoral nailing. International Journal of Orthopaedics Sciences 2017;3:319-23.

7. Kim SY, Kim YG, Hwang JK. Cementless calcar-replacement hemiarthroplasty compared with intramedullary fixation of unstable intertrochanteric fractures. A prospective, randomized study. J Bone Joint Surg Am 2005;87:2186-92.

8. Tomak Y, Kocaoglu M, Piskin A, Yildiz C, Gulman B, Tomak L. Treatment of intertrochanteric fractures in geriatric patients with a modified external fixator. Injury 2005;36:635-43.

9. Jones HW, Johnston P, Parker M. Are short femoral nails superior to the sliding hip screw? A meta-analysis of 24 studies involving 3,279 fractures. Int Orthop 2006;30:69-78.

10. Tang $\mathrm{P}, \mathrm{Hu} \mathrm{F}$, Shen J, Zhang L, Zhang L. Proximal femoral nail antirotation versus hemiarthroplasty: a study for the treatment of intertrochanteric fractures. Injury 2012;43:876-81.

11. Barton TM, Gleeson R, Topliss C, Greenwood R, Harries WJ, Chesser TJ. A comparison of the long gamma nail with the sliding hip screw for the treatment of AO/OTA 31-A2 fractures of the proximal part of the femur: a prospective randomized trial. J Bone Joint Surg Am 2010;92:792-8.

12. Jiang SD, Jiang LS, Zhao CQ, Dai LY. No advantages of Gamma nail over sliding hip screw in the management of peritrochanteric hip fractures: a meta-analysis of randomized controlled trials. Disabil Rehabil 2008;30:493-7. 
13. Bendo JA, Weiner LS, Strauss E, Yang E. Collapse of intertrochanteric hip fractures fixed with sliding screws. Orthop Rev 1994;Suppl:30-7.

14. Broos PL, Rommens PM, Geens VR, Stappaerts KH. Pertrochanteric fractures in the elderly. Is the Belgian VDP prosthesis the best treatment for unstable fractures with severe comminution? Acta Chir Belg 1991;91:242-9.

15. Boldin C, Seibert FJ, Fankhauser F, Peicha G, Grechenig W, Szyszkowitz R. The proximal femoral nail (PFN)--a minimal invasive treatment of unstable proximal femoral fractures: a prospective study of 55 patients with a followup of 15 months. Acta Orthop Scand 2003;74:53-8.

16. Friedl W, Clausen J. Experimental examination for optimized stabilisation of trochanteric femur fractures, intra- or extramedullary implant localisation and influence of femur neck component profile on cut-out risk. Chirurg 2001;72:1344-52.

17. Desteli EE, İmren $Y$, Erdoğan M, Aydagün Ö. Quality of life following treatment of trochanteric fractures with proximal femoral nail versus cementless bipolar hemiarthroplasty in elderly. Clin Invest Med 2015;38:E63-72.

18. Luo X, He S, Zeng D, Lin L, Li Q. Proximal femoral nail antirotation versus hemiarthroplasty in the treatment of senile intertrochanteric fractures: Case report. Int J Surg Case Rep 2017;38:37-42.

19. Rodop O, Kiral A, Kaplan H, Akmaz I. Primary bipolar hemiprosthesis for unstable intertrochanteric fractures. Int Orthop 2002;26:233-7. 